\title{
Plurilinguismo svizzero in coma?
}

Sergio Marengo

Corrispondenza:

Dr. Sergio Marengo

Via Patocchi 11

CH-6644 Orselina
Il plurilinguismo è sinonimo di Svizzera; lo chiamano anche la marcia in più o il jolly elvetico. Per sottolineare questa nostra straordinaria caratteristica e per avvertire sulle incombenti minacce alla nostra cultura, coscienza svizzera, e numerose altre organizzazioni culturali, hanno programmato dibattiti ed iniziative varie sul tema.

Su ciò i giornali hanno già informato. Si è poi felicemente coniata, e realizzata, la «tenda» del pluralismo, che ospiterà, con un percorso svizzero, personalità affermatesi in diversi campi. Perchè questa mobilitazione, quasi da ultima spiaggia?

Perchè, sul plurilinguismo elvetico, incombono ombre preoccupanti.

La campagna vuole sensibilizzare le cittadine ed i cittadini del nostro paese sulla crisi culturale (cioè sul declino, nel nostro paese, della lingua e cultura italiane).

Si tratta di motivate grida «al lupo», confermate da tre semplici considerazioni:

- La lingua italiana, come principale, è parlata dal 6,5\% degli svizzeri. Con gli stranieri arriviamo al 14,8\% (censimento 2000).

- Le riduzioni delle cattedre universitarie di italianistica, ora ridotte al lumicino, compromettono la nostra cultura. Tutti sanno che il cuore della cultura è l'università.

- L'impressionante perdita di purezza linguistica dell'italiano, parlato e scritto, vuol dire la scomparsa di un enorme, fondamentale patrimonio culturale.

«Il collante che tiene unito un popolo non è lo spazio, ma un insieme di valori.» Il futuro delle quattro culture svizzere dipenderà dai cittadini e dalle scelte politiche. Il rischio di perdere quasi tutto della nostra cultura, non solo svizzeroitaliana ma nazionale, è dietro l'angolo degli anni a venire, neppure lontani.

La comparsa, recentissima, nel cielo di Lugano della «cometa USI» (la nuova facoltà di scienze umane), ci permette solo di mitigare un ragionevole pessimismo. Per far tornare il sereno tutti dobbiamo impegnarci. Per ogni essere umano la lingua madre è vicina al cuore.

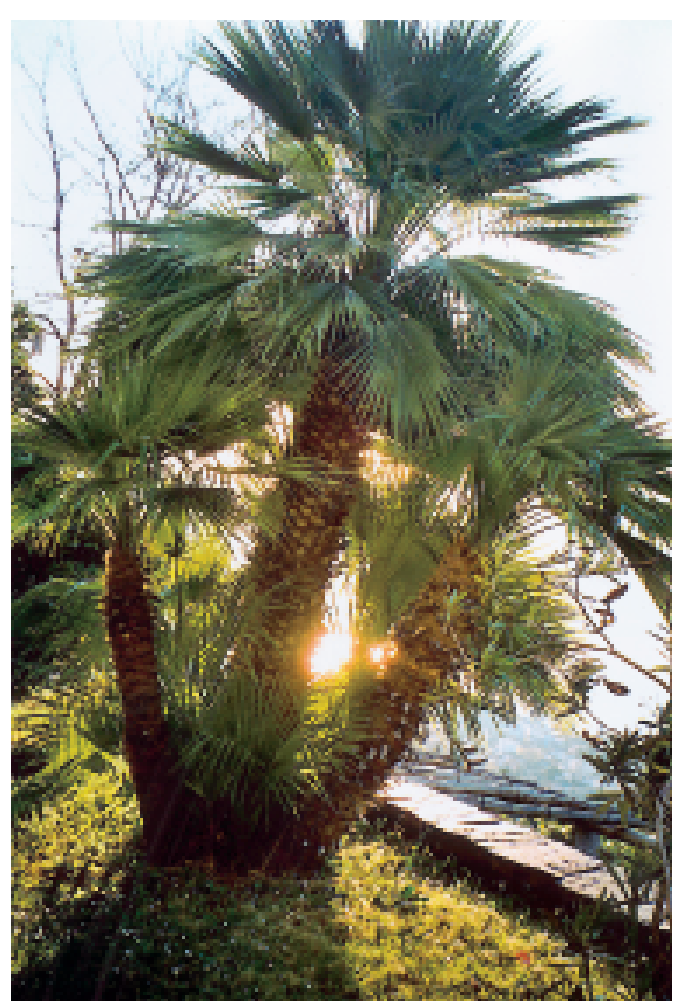

